\title{
Stroke symptoms and risk for incident coronary heart disease in the REasons for Geographic And Racial Differences in Stroke (REGARDS) Study
}

\author{
Lisandro D. Colantonio, MD MSc ${ }^{1}$, Christopher M. Gamboa, MPH $^{2}$, Dawn O. Kleindorfer, \\ MD³ , April P. Carson, PhD11, Virginia J. Howard, PhD1, Paul Muntner, PhD', Mary Cushman, \\ MD $^{4}$, George Howard, DrPH ${ }^{5}$, and Monika M. Safford, MD ${ }^{2}$ \\ ${ }^{1}$ Department of Epidemiology, School of Public Health, University of Alabama at Birmingham, \\ Birmingham, AL. \\ 2 Department of Medicine, School of Medicine, University of Alabama at Birmingham, \\ Birmingham, AL. \\ ${ }^{3}$ Department of Neurology, School of Medicine, University of Cincinnati, Cincinnati, $\mathrm{OH}$. \\ ${ }^{4}$ Department of Medicine, School of Medicine, University of Vermont, Burlington, VT. \\ ${ }^{5}$ Department of Biostatistics, School of Public Health, University of Alabama at Birmingham, \\ Birmingham, AL.
}

\begin{abstract}
Background-Many adults without cerebrovascular disease report a history of stroke symptoms, which is associated with higher risk for stroke. Because stroke and coronary heart disease (CHD) share many risk factors, we examined the association between a history of stroke symptoms and incident CHD.
\end{abstract}

Methods-We analyzed data from 8,999 black and 12,499 white REasons for Geographic And Racial Differences in Stroke (REGARDS) study participants without a prior myocardial infarction, stroke or transitory ischemic attack enrolled in 2003-2007 (total participants $=21,498$, all $\geq 45$ years of age). A history of stroke symptoms (i.e., unilateral weakness, unilateral numbness, full-field vision loss, half-field vision loss, understanding problems and communication problems) was assessed at baseline using the Questionnaire for Verifying Stroke-Free Status. Participants were followed for incident CHD and CHD death through December 2011.

\footnotetext{
Corresponding author: Monika M. Safford, MD, General Internal Medicine, Weill Cornell Medicine, 1300 York Avenue, F2006, New York, NY 10065. mms9024@med.cornell.edu, Telephone: (212) 746-3026, Fax: (212) 746-1014.

Publisher's Disclaimer: This is a PDF file of an unedited manuscript that has been accepted for publication. As a service to our customers we are providing this early version of the manuscript. The manuscript will undergo copyediting, typesetting, and review of the resulting proof before it is published in its final citable form. Please note that during the production process errors may be discovered which could affect the content, and all legal disclaimers that apply to the journal pertain.

All authors take responsibility for all aspects of the reliability and freedom from bias of the data presented and their discussed interpretation.

Disclosures

PM and MMS received grant support from Amgen Inc. MC is consultant from Merck \& Co., Inc., and has received grant funding and speaker honorarium from Diadexus, Inc. LDC, CMG, DOK, APC, VJH and GH have no disclosures to report. All co-authors have reviewed and approved this manuscript.
} 
Results-Overall, 3,432 (16.0\%) participants reported a history of stroke symptoms (1,771 [19.7\%] blacks and 1,661 [13.3\%] whites). There were 701 incident CHD events including 209 CHD deaths over a median follow-up of 5.8 years. After adjustment for CHD risk factors, hazard ratios $(95 \%$ confidence interval $[95 \% \mathrm{CI}]$ ) for incident $\mathrm{CHD}$ associated with reporting any versus no stroke symptoms were 1.26 (1.04-1.51) in the overall population, 1.28 (0.99-1.65) among blacks and 1.23 (0.94-1.61) among whites. Multivariable-adjusted hazard ratios (95\% CI) for CHD death associated with any versus no stroke symptoms were 1.50 (1.10-2.06) overall, 1.58 (1.07-2.32) among blacks and 1.41 (0.82-2.43) among whites.

Conclusion-A history of stroke symptoms is associated with a higher incidence of CHD among black and white adults.

\section{Keywords}

Coronary disease; risk factors; cerebrovascular disorders; epidemiology

\section{Introduction}

Cerebrovascular disease is associated with a higher risk for coronary heart disease (CHD). Individuals with a history of stroke or transient ischemic attack (TIA) have a high absolute risk for CHD events, similar to those with a history of CHD. ${ }^{1,2}$ Also, having a carotid artery plaque or increased carotid wall-thickness is associated with a higher risk for CHD among individuals without a history of stroke or TIA, ${ }^{3-5}$ with even larger increase risk of CHD than risk of stroke. ${ }^{5}$ We recently reported that a history of stroke symptoms is present in as many as $18 \%$ of individuals without known stroke or TIA history, and is associated with stroke risk factors, cognitive impairment, and increased risk for future stroke. ${ }^{6-9}$ Taken together, these results suggest that a history of stroke symptoms may be a marker of cerebrovascular disease and, possibly, CHD risk.

Many individuals with stroke symptoms do not seek medical attention. ${ }^{10}$ Therefore, it is possible that screening for a history of stroke symptoms could be a novel strategy for identifying a substantial number of individuals with elevated risk for future CHD, including those who currently do not engage in regular healthcare. However, the association between stroke symptoms and incident CHD has not been well examined. If such an association exists, a history of stroke symptoms could be incorporated as part of low-cost risk assessment tools to facilitate the detection of individuals at high risk for CHD in primary care and population screening programs. This is especially important for black Americans, who are at twice the risk for dying at their presentation with CHD compared to white Americans. ${ }^{11}$ Strategies that can be widely applied to identify high risk individuals without relying on blood testing or physiologic measures would aid in eliminating this health disparity, but such tools are currently not well developed.

We used data from the REasons for Geographic And Racial Differences in Stroke (REGARDS) study to analyze the association between a history of stroke symptoms and incident CHD. We hypothesized that a history of stroke symptoms would be associated with incident CHD in both black and white Americans. 


\section{Methods}

\subsection{Study Population}

The REGARDS study was designed to investigate reasons underlying the higher rate of stroke mortality among blacks compared to whites, and among residents of the Southeastern US versus other US regions. ${ }^{12}$ CHD events are being identified and adjudicated in an ancillary study. ${ }^{11}$ A total of 30,239 black and white men and women $\geq 45$ years of age from all 48 contiguous US states and the District of Columbia were enrolled between January 2003 and October 2007. Blacks and residents from the stroke buckle (coastal North Carolina, South Carolina and Georgia) and stroke belt (remaining parts of the stroke buckle states and Tennessee, Mississippi, Alabama, Louisiana and Arkansas) were oversampled by design.

For the present analysis, we excluded REGARDS study participants without post-baseline contacts to assess the occurrence of incident CHD ( $n=545)$ or with a history of atherosclerotic cardiovascular disease (ASCVD) at baseline as defined below $(n=8,196)$. The REGARDS study protocol was approved by the Institutional Review Boards governing research in human subjects at the participating centers and all participants provided written informed consent.

\subsection{Baseline assessment}

Computer-assisted telephone interviews (CATI) were administered by trained staff and used to collect self-reported information on participants' age, race, gender, household income and education levels, smoking status, physical activity, prior diagnosed comorbid conditions (i.e., myocardial infarction [MI], stroke, TIA and diabetes), history of vascular procedures (including coronary, carotid and lower extremity artery revascularization, and aortic aneurysm repair surgery), and use of antihypertensive and antidiabetes medications.

After the CATI, a trained health professional conducted an in-home examination following standardized protocols. Procedures included a waist circumference measurement, two blood pressure measurements after a 5 minutes rest which were averaged, an electrocardiogram, collection of blood and urine samples, and an inventory of all medications taken within the 2 weeks prior to the study visit. Using blood samples, serum total cholesterol, high-density lipoprotein (HDL) cholesterol, triglycerides, glucose, creatinine and high-sensitivity Creactive protein (hsCRP) were measured. Urinary albumin and creatinine were measure using urine samples.

History of ASCVD at baseline was defined as a self-report of a prior diagnosis of MI, stroke or TIA; a prior coronary artery bypass, coronary angioplasty or stenting; a carotid revascularization; a lower extremity artery revascularization procedure or an aortic aneurysm repair surgery; or evidence of a previous MI on the study electrocardiogram. Current smoking was defined by reporting having smoked more than 100 cigarettes in lifetime and currently smoking cigarettes, even occasionally. Any exercise was defined by reporting engaging in a physical activity intense enough to work up a sweat at least once a week. Diabetes was defined as fasting glucose $\geq 126 \mathrm{mg} / \mathrm{dL}$, non-fasting glucose $\geq 200 \mathrm{mg} / \mathrm{dL}$, or self-report of a prior diagnosis of diabetes and current antidiabetes medication use. 
Estimated glomerular filtration rate (eGFR) was calculated using the equation from the Chronic Kidney Disease Epidemiology Collaboration which includes age, race, gender, and serum creatinine ${ }^{13}$ Urinary albumin and creatinine were used to calculate the albumin-tocreatinine ratio (ACR). Current statin use was defined by having a statin in the medication inventory.

\subsection{Stroke symptoms}

As part of their baseline CATI, REGARDS study participants were asked if they had ever experienced each of 6 stroke symptoms using the Questionnaire for Verifying Stroke-Free Status (QVSFS). ${ }^{14}$ Stroke symptoms assessed include: unilateral weakness ("Have you ever had sudden painless weakness on one side of your body?"), unilateral numbness ("Have you ever had sudden numbness or a dead feeling on one side of your body?"), full-field vision loss ("Have you ever had sudden painless loss of vision in one or both eyes?"), half-field vision loss ("Have you ever suddenly lost one half of your vision?"), problems with understanding ("Have you ever suddenly lost the ability to understand what people were saying?"), and problems with communication ("Have you ever suddenly lost the ability to express yourself verbally or in writing?").

\subsection{CHD outcomes}

REGARDS study participants or proxy respondents were contacted every 6 months via telephone to assess incident CHD events. When non-fatal events were reported, medical records were retrieved for adjudication. When fatal CHD events were reported, interviews with next-of-kin or proxies, medical records in the last year of life, death certificates and autopsy reports were examined to determine if a CHD event was the main underlying cause of death. Non-fatal MIs and fatal CHD events were adjudicated by trained clinicians following published guidelines. ${ }^{15-17}$ The primary study outcome was incident CHD, defined as an incident definite or probable non-fatal MI or CHD death. ${ }^{11}$ A secondary study outcome, CHD death, was defined as a definite or probable CHD death. For the current analysis, participants were followed through the date of their incident CHD event, death, last study contact or December 31, 2011, whichever occurred first.

\subsection{Statistical analysis}

We calculated the proportion of REGARDS study participants who reported any and separately, each of the 6 stroke symptoms at baseline. Baseline characteristics of participants with and, separately, without stroke symptoms were summarized using proportions for categorical data and mean and standard deviation or median and $25^{\text {th }}-75^{\text {th }}$ percentiles for continuous data.

We used the Kaplan-Meier method to calculate the cumulative incidence of CHD over time among REGARDS study participants with and without stroke symptoms, separately. We also calculated CHD incidence rates among REGARDS study participants with and separately, without stroke symptoms. We used Cox-proportional hazard regression models to estimate hazard ratios for incident CHD associated with reporting any versus none of the 6 stroke symptoms. In addition to the unadjusted model (Model 1), three models with progressive adjustment for covariates were used. Model 2 includes adjustment for age, 
gender, race, region of residence (i.e., stroke buckle, stroke belt, and non-belt/non-buckle), income and education. Model 3 includes covariates in Model 2 plus cigarette smoking, systolic blood pressure, diabetes, total cholesterol, HDL cholesterol, antihypertensive medication use and statin use. Model 4 includes adjustment for Model 3 covariates plus physical activity, waist circumference, ACR, hsCRP and eGFR. We included interaction terms in the Cox-proportional hazard regression models to analyze the effect modification on the association between stroke symptoms and incident CHD by age, gender, race, education and income.

We calculated CHD incidence rates among REGARDS study participants who reported none, 1, 2 or $\geq 3$ of the 6 stroke symptoms at baseline. Cox-proportional hazard regression models with the same adjustment as described above were used to estimate hazard ratios for incident CHD associated with reporting 1, 2 or $\geq 3$ stroke symptoms at baseline, each versus reporting none of the 6 stroke symptoms. Trends in the hazard ratios were analyzed by modeling the number of stroke symptoms as an ordinal variable.

We analyzed the association of each of the 6 stroke symptoms, separately, with incident CHD using Cox-proportional hazard regression models with the same adjustment as described above. Some stroke symptoms may be not associated with incident CHD. In a secondary analysis, we estimated hazard ratios for incident CHD associated with a history of any of the stroke symptoms which were statistically significant in unadjusted models (Model 1) when analyzed separately. We repeated analyses described above using CHD death as outcome. All analyses were conducted overall and stratified by race.

We used multiple imputation to estimate hazard ratios for incident CHD and CHD death in order to include in the analysis REGARDS participants with missing covariates (Supplemental Table 1). Multiple imputation was conducted using chained equations to obtain 10 imputed datasets, with each dataset produced after 10 cycles of imputations. ${ }^{18,19}$ Analyses with multiply imputed data were performed in Stata 12 (Stata Corp, College Station, TX) with other analyses conducted using SAS 9.3 (SAS Institute, Cary, NC). All analyses were performed using a 2-sided level of significance alpha $<0.05$.

\section{Results}

A total of 21,498 REGARDS study participants with follow-up for CHD events were free of ASCVD at baseline and were included in the current analysis. Overall, 3,432 (16.0\%) participants reported a history of stroke symptoms at baseline (Table 1). The proportion of participants who reported a history of stroke symptoms was higher among blacks versus whites. Unilateral numbness was the stroke symptom most frequently reported, followed by unilateral weakness. REGARDS study participants who reported a history of stroke symptoms were more likely to be black, female, have low income and education, be a current smoker, take antihypertensive medication, have diabetes, and be less likely to engage in any exercise as compared with those reporting no history of stroke symptoms at baseline (Table 2). 
There were 701 incident CHD events including 209 CHD deaths over a median follow-up of 5.8 years (maximum follow-up: 8.9 years). Participants who reported a history of stroke symptoms had a higher cumulative incidence and incidence rate for CHD and CHD death as compared to those reporting no history of stroke symptoms at baseline (Figure 1, left panels and Table 3). In the overall population, unadjusted hazard ratios (95\% confidence interval [CI]) for incident CHD and CHD death associated with a history of stroke symptoms were $1.45(1.21,1.74)$ and $1.89(1.38,2.58)$, respectively. These associations remained statistically significant after multivariable adjustment. Both blacks and whites who reported a history of stroke symptoms had higher risk for CHD and CHD death compared with their counterparts without stroke symptoms when analyzed separately, although the association with CHD death was not statistically significant among whites (Figure 1, right panels and Table 4). Unadjusted hazard ratios (95\% CI) for incident CHD associated with a history of stroke symptoms were $1.55(1.20,2.00)$ among blacks and $1.33(1.02,1.74)$ among whites. Hazard ratios for incident CHD were similar among blacks and whites after multivariable adjustment. Unadjusted hazard ratios (95\% CI) for CHD death associated with a history of stroke symptoms were $1.86(1.26,2.75)$ among blacks and $1.60(0.94,2.71)$ among whites. After multivariable adjustment, hazard ratios $(95 \% \mathrm{CI})$ for CHD death were 1.58 (1.07, $2.32)$ and $1.41(0.82,2.43)$ among blacks and whites, respectively. No effect modification on the association of a history of stroke symptoms with incident CHD and CHD death was present by race, age, gender, household income and education (all p-values $>0.05$ ).

Multivariable-adjusted hazard ratios for incident CHD and CHD death did not increase with a higher number of stroke symptoms reported at baseline in the overall population (Supplemental Table 2). Results were consistent with this finding when the analysis was conducted by race (Supplemental Tables 3 and $\mathbf{4}$ ).

Full-field vision loss, problems with communication, half-field vision loss and problems with understanding were associated with a higher risk for incident CHD and CHD death in unadjusted models (Model 1) in the overall population (Supplemental Tables 5 and 6). After multivariable adjustment, full-field vision loss, problems with communication and problems with understanding were associated with a higher risk for incident CHD (Figure

2). Problems with understanding were also associated with a higher risk for CHD death after multivariable adjustment. A similar pattern was observed among blacks and whites when analyzed separately.

In the secondary analysis, we estimated the association of a history of any of the 4 stroke symptoms which were associated with incident CHD and CHD death, separately in unadjusted models in the overall population (i.e., full-field vision loss, problems with communication, half-field vision loss and problems with understanding). Unadjusted hazard ratios (95\% CI) for incident CHD and CHD death associated with reporting any versus none of the 4 stroke symptoms in the overall population were $1.69(1.36,2.09)$ and $2.19(1.52$, 3.15), respectively (Supplemental Table 7). Hazard ratios for incident CHD and CHD death in the overall population remained statistically significant after multivariable adjustment. Multivariable-adjusted hazard ratios for incident CHD were similar among blacks and whites (Supplemental Table 8). After multivariable adjustment, hazard ratios (95\% CI) for 
CHD death associated with reporting any versus none of the 4 stroke symptoms were 1.85 $(1.18,2.90)$ among blacks and $1.46(0.78,2.72)$ among whites.

\section{Discussion}

In this analysis of a large population-based cohort, $16 \%$ of participants without a history of ASCVD reported a history of stroke symptoms, and these participants had a higher risk for incident CHD and CHD death as compared with their counterparts without stroke symptoms. The association of stroke symptoms with incident CHD and CHD death was similar among blacks and whites. Results from the current analysis suggest that screening for stroke symptoms could identify adults with a higher risk for CHD.

Many individuals with stroke symptoms do not seek medical attention. ${ }^{10}$ This represents a lost opportunity for primary prevention of CHD. The association between stroke symptoms and CHD provides a low-cost and low-technology tool which can be used to screen populations to detect individuals with a higher risk for incident CHD and CHD death. Conducting the QVSFS involves minimal training and requires less than 5 minutes. ${ }^{14}$ Because this is a very short questionnaire, it is likely to be perceived as unobtrusive and it could be combined with other low-cost screening tools including blood pressure measurements. A compelling possibility from the perspective of racial disparities is the opportunity for using stroke symptoms to screen black populations to identify high risk candidates for preventive interventions. This could contribute to reducing the excess of risk for acute CHD death at presentation among black Americans, a long standing disparity that has shown little evidence of resolution in the modern era. ${ }^{11}$ Such interventions could also contribute to reduce the risk for stroke among black Americans. ${ }^{12,}{ }^{20}$ Specifically, stroke symptoms questionnaires could be used in health fairs and church-based programs in black communities to identify individuals with high risk for CHD and stroke who currently do not engage in healthcare. ${ }^{21,22}$ Church-based health programs have shown a great potential to promote a positive change in health behaviors and improve control of cardiovascular risk factors among blacks. ${ }^{22-25}$ Future prospective studies are needed to investigate whether screening for stroke symptoms could contribute to prevent CHD and stroke events in primary care or population-based interventions.

Prior studies have shown that individuals with cerebrovascular disease have an increased risk for CHD. ${ }^{1-5,26}$ Using data from the Multi-Ethnic Study of Atherosclerosis (MESA), Polak et al. reported that participants without a history of stroke or CHD who have an atherosclerotic plaque in their carotid artery have a hazard ratio for incident CHD of 1.67 (95\% CI: $1.33,2.10)$ as compared with those without atherosclerotic plaques. ${ }^{3}$ Also, individuals with a history of stroke or TIA have a high absolute risk for CHD events, similar to those with a prior history of CHD. ${ }^{1}$ The absolute risk for myocardial infarction following a stroke or TIA was $2.2 \%$ per year (>20\% over 10 years) in a meta-analysis conducted by Touzé et al. ${ }^{2}$ Results from the current study extend these prior findings by showing that individuals without a history of stroke or TIA who report stroke symptoms have an increased risk for incident $\mathrm{CHD}$ and $\mathrm{CHD}$ death. 
Prior studies support the hypothesis that many adults without a history of stroke or TIA who report stroke symptoms may have undetected cerebrovascular disease. ${ }^{9,} 27$ Among individuals without a history of stroke or TIA, stroke symptoms are associated with cerebrovascular risk factors, including black race, diabetes, hypertension and smoking, and a higher Framingham Stroke Risk score and carotid intima media wall thickness. ${ }^{6,7,28,} 29$ In addition, stroke symptoms have been shown to be associated with a higher risk for incident cognitive impairment and stroke. ${ }^{9}, 20,30-32$ In the REGARDS study, the multivariableadjusted hazard ratio for incident stroke associated with reporting any versus none of the 6 stroke symptoms assessed through the QVSFS was 1.36 (95\% CI: 1.08, 1.72). ${ }^{9}$ It is noteworthy that the strength of the association with incident CHD (hazard ratio: 1.26) and CHD death (1.50) observed in our study is remarkably similar to the size of the association with incident stroke.

Not all individuals reporting stroke symptoms have undetected cerebrovascular disease. Several conditions, including epileptic seizures, migraine attacks and psychogenic hyperventilation, could mimic stroke symptoms. ${ }^{33}$ The 6 questions from the QVSFS used here inquire specifically about the occurrence of symptoms characterized as focal, sudden, and painless that could represent clinically undetected cerebrovascular events. ${ }^{34}$ However, some REGARDS study participants who reported stroke symptoms during follow-up had an alternate explanation which does not involve a cerebrovascular event. ${ }^{6}$ For example, participants reporting sudden painless weakness or numbness indicated that they have a condition related to their hip or spine, or surgery which could potentially explain their symptoms. Indeed, we observed no association with CHD for the symptoms of unilateral weakness or numbness.

The QVSFS has high sensitivity and negative predictive value but lower specificity and positive predictive value for a history of stroke or TIA as compared with review of medical records or examination by a trained neurologist. ${ }^{14,35,36}$ Unilateral numbness and weakness were the least specific stroke symptoms for a history of stroke or TIA in prior studies, ${ }^{35,36}$ which can explain their lack of association with incident CHD in the current analysis. Excluding questions with low specificity from the QVSFS may increase the strength of the association between stroke symptoms and CHD. ${ }^{36}$ In the current analysis, including only full-field vision loss, half-field vision loss, problems with understanding and problems with communication increased the hazard ratio for incident CHD associated with stroke symptoms from 1.26 to 1.40 . Other strategies that could be used to increase the specificity of stroke symptoms include combining questions to reflect the most common stroke syndromes, such as dysarthria-clumsy hand syndrome, and excluding episodes requiring medical attention that were characterized as noncerebrovascular by a physician. ${ }^{33,} 36$ Future studies should investigate whether some of these strategies could increase the specificity of stroke symptoms to identify individuals with cerebrovascular disease and higher risk for CHD without a substantial loss in sensitivity.

The current study has many strengths. The REGARDS study is a large population-based cohort representative of black and white Americans $\geq 45$ years of age and stroke symptoms were assessed using a validated questionnaire with high interrater reliability. ${ }^{14,34,36}$ The REGARDS study collected data on several cardiovascular risk factors allowing this study to 
include many potential confounders, and the CHD outcomes were rigorously adjudicated. The current study is not without limitations. Information on whether participants reporting stroke symptoms sought care or had concurrent conditions which can mimic cerebrovascular events was not collected at baseline. Brain imagining is not available in the REGARDS study, and a history of stroke or TIA was defined by self-report. Many REGARDS participants who reported stroke symptoms may not recall receiving a diagnosis of stroke or TIA.

In conclusion, many individuals without a history of ASCVD report stroke symptoms, and are at increased risk for incident CHD and CHD death. Screening for stroke symptoms in primary care and community-based programs could identify individuals with high CHD risk. If preventive interventions could be targeted at large numbers of previously undetected highrisk individuals, the long-standing disparity in risk for death at presentation with CHD currently faced by black Americans could potentially be alleviated.

\section{Supplementary Material}

Refer to Web version on PubMed Central for supplementary material.

\section{Acknowledgements}

This research project is supported by a cooperative agreement U01 NS041588 from the National Institute of Neurological Disorders and Stroke, National Institutes of Health, Department of Health and Human Service. Representatives of the funding agency have been involved in the review of the manuscript but not directly involved in the collection, management, analysis or interpretation of the data. Additional support was provided by grants R01 HL080477 and K24 HL111154 from the National Heart, Lung, and Blood Institute. The content is solely the responsibility of the authors and does not necessarily represent the official views of the National Institute of Neurological Disorders and Stroke or the National Institutes of Health.

The authors thank the other investigators, the staff, and the participants of the REGARDS study for their valuable contributions. A full list of participating REGARDS investigators and institutions and further information about the study can be found at http://www.regardsstudy.org.

\section{References}

1. Third Report of the National Cholesterol Education Program (NCEP) Expert Panel on Detection, Evaluation, and Treatment of High Blood Cholesterol in Adults (Adult Treatment Panel III) final report. Circulation. 2002; 106:3143-3421. [PubMed: 12485966]

2. Touze E, Varenne O, Chatellier G, Peyrard S, Rothwell PM, Mas JL. Risk of myocardial infarction and vascular death after transient ischemic attack and ischemic stroke: a systematic review and meta-analysis. Stroke; a journal of cerebral circulation. 2005; 36:2748-2755.

3. Polak JF, Szklo M, Kronmal RA, Burke GL, Shea S, Zavodni AE, O'Leary DH. The value of carotid artery plaque and intima-media thickness for incident cardiovascular disease: the multi-ethnic study of atherosclerosis. Journal of the American Heart Association. 2013; 2:e000087. [PubMed: 23568342]

4. Chambless LE, Heiss G, Folsom AR, Rosamond W, Szklo M, Sharrett AR, Clegg LX. Association of coronary heart disease incidence with carotid arterial wall thickness and major risk factors: the Atherosclerosis Risk in Communities (ARIC) Study, 1987-1993. American journal of epidemiology. 1997; 146:483-494. [PubMed: 9290509]

5. O'Leary DH, Polak JF, Kronmal RA, Manolio TA, Burke GL, Wolfson SK Jr. Carotid-artery intima and media thickness as a risk factor for myocardial infarction and stroke in older adults. Cardiovascular Health Study Collaborative Research Group. The New England journal of medicine. 1999; 340:14-22. [PubMed: 9878640] 
6. Howard VJ, McClure LA, Meschia JF, Pulley L, Orr SC, Friday GH. High prevalence of stroke symptoms among persons without a diagnosis of stroke or transient ischemic attack in a general population: the REasons for Geographic And Racial Differences in Stroke (REGARDS) study. Archives of internal medicine. 2006; 166:1952-1958. [PubMed: 17030827]

7. Gao L, Meschia JF, Judd SE, Muntner P, McClure LA, Howard VJ, Rhodes JD, Cushman M, Safford MM, Soliman EZ, Kleindorfer DO, Howard G. What stroke symptoms tell us: association of risk factors and individual stroke symptoms in the REasons for Geographic And Racial Differences in Stroke (REGARDS) study. Journal of stroke and cerebrovascular diseases : the official journal of National Stroke Association. 2012; 21:411-416. [PubMed: 22726606]

8. Wadley VG, McClure LA, Howard VJ, Unverzagt FW, Go RC, Moy CS, Crowther MR, Gomez CR, Howard G. Cognitive status, stroke symptom reports, and modifiable risk factors among individuals with no diagnosis of stroke or transient ischemic attack in the REasons for Geographic And Racial Differences in Stroke (REGARDS) Study. Stroke; a journal of cerebral circulation. 2007; 38:11431147.

9. Kleindorfer D, Judd S, Howard VJ, McClure L, Safford MM, Cushman M, Rhodes D, Howard G. Self-reported stroke symptoms without a prior diagnosis of stroke or transient ischemic attack: a powerful new risk factor for stroke. Stroke; a journal of cerebral circulation. 2011; 42:3122-3126.

10. Howard VJ, Lackland DT, Lichtman JH, McClure LA, Howard G, Wagner L, Pulley L, Gomez CR. Care seeking after stroke symptoms. Annals of neurology. 2008; 63:466-472. [PubMed: 18360830]

11. Safford MM, Brown TM, Muntner PM, Durant RW, Glasser S, Halanych JH, Shikany JM, Prineas RJ, Samdarshi T, Bittner VA, Lewis CE, Gamboa C, Cushman M, Howard V, Howard G. Association of race and sex with risk of incident acute coronary heart disease events. JAMA : the journal of the American Medical Association. 2012; 308:1768-1774. [PubMed: 23117777]

12. Howard VJ, Cushman M, Pulley L, Gomez CR, Go RC, Prineas RJ, Graham A, Moy CS, Howard G. The REasons for Geographic And Racial Differences in Stroke Study: objectives and design. Neuroepidemiology. 2005; 25:135-143. [PubMed: 15990444]

13. Levey AS, Stevens LA, Schmid CH, Zhang YL, Castro AF 3rd, Feldman HI, Kusek JW, Eggers P, Van Lente F, Greene T, Coresh J. A new equation to estimate glomerular filtration rate. Annals of internal medicine. 2009; 150:604-612. [PubMed: 19414839]

14. Meschia JF, Brott TG, Chukwudelunzu FE, Hardy J, Brown RD Jr. Meissner I, Hall LJ, Atkinson EJ, O'Brien PC. Verifying the stroke-free phenotype by structured telephone interview. Stroke; a journal of cerebral circulation. 2000; 31:1076-1080.

15. Luepker RV, Apple FS, Christenson RH, Crow RS, Fortmann SP, Goff D, Goldberg RJ, Hand MM, Jaffe AS, Julian DG, Levy D, Manolio T, Mendis S, Mensah G, Pajak A, Prineas RJ, Reddy KS, Roger VL, Rosamond WD, Shahar E, Sharrett AR, Sorlie P, Tunstall-Pedoe H. Case definitions for acute coronary heart disease in epidemiology and clinical research studies: a statement from the AHA Council on Epidemiology and Prevention; AHA Statistics Committee; World Heart Federation Council on Epidemiology and Prevention; the European Society of Cardiology Working Group on Epidemiology and Prevention; Centers for Disease Control and Prevention; and the National Heart, Lung, and Blood Institute. Circulation. 2003; 108:2543-2549. [PubMed: 14610011]

16. Prineas, RJ.; Crow, RS.; Blackburn, H. The Minnesota code manual of electrocardiographic findings: Standards and procedures for measurement and classification. Wright-OSG; Boston, MA: 1982.

17. Thygesen K, Alpert JS, White HD, Jaffe AS, Apple FS, Galvani M, Katus HA, Newby LK, Ravkilde J, Chaitman B, Clemmensen PM, Dellborg M, Hod H, Porela P, Underwood R, Bax JJ, Beller GA, Bonow R, Van der Wall EE, Bassand JP, Wijns W, Ferguson TB, Steg PG, Uretsky BF, Williams DO, Armstrong PW, Antman EM, Fox KA, Hamm CW, Ohman EM, Simoons ML, Poole-Wilson PA, Gurfinkel EP, Lopez-Sendon JL, Pais P, Mendis S, Zhu JR, Wallentin LC, Fernandez-Aviles F, Fox KM, Parkhomenko AN, Priori SG, Tendera M, Voipio-Pulkki LM, Vahanian A, Camm AJ, De Caterina R, Dean V, Dickstein K, Filippatos G, Funck-Brentano C, Hellemans I, Kristensen SD, McGregor K, Sechtem U, Silber S, Tendera M, Widimsky P, Zamorano JL, Morais J, Brener S, Harrington R, Morrow D, Lim M, Martinez-Rios MA, Steinhubl 
S, Levine GN, Gibler WB, Goff D, Tubaro M, Dudek D, Al-Attar N. Universal definition of myocardial infarction. Circulation. 2007; 116:2634-2653. [PubMed: 17951284]

18. Sterne JA, White IR, Carlin JB, Spratt M, Royston P, Kenward MG, Wood AM, Carpenter JR. Multiple imputation for missing data in epidemiological and clinical research: potential and pitfalls. BMJ (Clinical research ed.). 2009; 338:b2393.

19. White IR, Royston P, Wood AM. Multiple imputation using chained equations: Issues and guidance for practice. Statistics in medicine. 2011; 30:377-399. [PubMed: 21225900]

20. Judd SE, Kleindorfer DO, McClure LA, Rhodes JD, Howard G, Cushman M, Howard VJ. Selfreport of stroke, transient ischemic attack, or stroke symptoms and risk of future stroke in the REasons for Geographic And Racial Differences in Stroke (REGARDS) study. Stroke; a journal of cerebral circulation. 2013; 44:55-60.

21. Wilson LC. Implementation and evaluation of church-based health fairs. Journal of community health nursing. 2000; 17:39-48. [PubMed: 10778028]

22. Campbell MK, Hudson MA, Resnicow K, Blakeney N, Paxton A, Baskin M. Church-based health promotion interventions: evidence and lessons learned. Annual review of public health. 2007; 28:213-234.

23. Aycock DM, Kirkendoll KD, Gordon PM. Hypertension education and screening in African American churches. Journal of community health nursing. 2013; 30:16-27. [PubMed: 23384064]

24. Frank D, Grubbs L. A faith-based screening/education program for diabetes, CVD, and stroke in rural African Americans. The ABNF journal : official journal of the Association of Black Nursing Faculty in Higher Education, Inc. 2008; 19:96-101.

25. Yanek LR, Becker DM, Moy TF, Gittelsohn J, Koffman DM. Project Joy: faith based cardiovascular health promotion for African American women. Public health reports (Washington, D.C. : 1974). 2001; 116(Suppl 1):68-81.

26. Burns JD, Rabinstein AA, Roger VL, Stead LG, Christianson TJ, Killian JM, Brown RD Jr. Incidence and predictors of myocardial infarction after transient ischemic attack: a populationbased study. Stroke; a journal of cerebral circulation. 2011; 42:935-940.

27. Howard G, Safford MM, Meschia JF, Moy CS, Howard VJ, Pulley L, Gomez CR, Crowther M. Stroke symptoms in individuals reporting no prior stroke or transient ischemic attack are associated with a decrease in indices of mental and physical functioning. Stroke; a journal of cerebral circulation. 2007; 38:2446-2452.

28. Carson AP, Muntner P, Kissela BM, Kleindorfer DO, Howard VJ, Meschia JF, Williams LS, Prineas RJ, Howard G, Safford MM. Association of prediabetes and diabetes with stroke symptoms: the REasons for Geographic And Racial Differences in Stroke (REGARDS) study. Diabetes care. 2012; 35:1845-1852. [PubMed: 22699292]

29. Chambless LE, Shahar E, Sharrett AR, Heiss G, Wijnberg L, Paton CC, Sorlie P, Toole JF. Association of transient ischemic attack/stroke symptoms assessed by standardized questionnaire and algorithm with cerebrovascular risk factors and carotid artery wall thickness. The ARIC Study, 1987-1989. American journal of epidemiology. 1996; 144:857-866. [PubMed: 8890664]

30. Chambless LE, Toole JF, Nieto FJ, Rosamond W, Paton C. Association between symptoms reported in a population questionnaire and future ischemic stroke: the ARIC study. Neuroepidemiology. 2004; 23:33-37. [PubMed: 14739565]

31. Hart CL, Hole DJ, Smith GD. The relation between questions indicating transient ischaemic attack and stroke in 20 years of follow up in men and women in the Renfrew/Paisley Study. Journal of epidemiology and community health. 2001; 55:653-656. [PubMed: 11511644]

32. Kelley BJ, McClure LA, Letter AJ, Wadley VG, Unverzagt FW, Kissela BM, Kleindorfer D, Howard G. Report of stroke-like symptoms predicts incident cognitive impairment in a stroke-free cohort. Neurology. 2013; 81:113-118. [PubMed: 23783751]

33. Amort M, Fluri F, Schafer J, Weisskopf F, Katan M, Burow A, Bucher HC, Bonati LH, Lyrer PA, Engelter ST. Transient ischemic attack versus transient ischemic attack mimics: frequency, clinical characteristics and outcome. Cerebrovascular diseases (Basel, Switzerland). 2011; 32:57-64.

34. Meschia JF, Lojacono MA, Miller MJ, Brott TG, Atkinson EJ, O'Brien PC. Reliability of the questionnaire for verifying stroke-free status. Cerebrovascular diseases (Basel, Switzerland). 2004; $17: 218-223$. 
35. Jones WJ, Williams LS, Meschia JF. Validating the Questionnaire for Verifying Stroke-Free Status (QVSFS) by neurological history and examination. Stroke; a journal of cerebral circulation. 2001; 32:2232-2236.

36. Sung VW, Johnson N, Granstaff US, Jones WJ, Meschia JF, Williams LS, Safford MM. Sensitivity and specificity of stroke symptom questions to detect stroke or transient ischemic attack.

Neuroepidemiology. 2011; 36:100-104. [PubMed: 21311197] 


\section{Highlights}

- Many adults without known cerebrovascular disease have had stroke symptoms.

- Stroke symptoms are associated with coronary heart disease (CHD) incidence.

- Screening for stroke symptoms can identify adults with high CHD risk. 


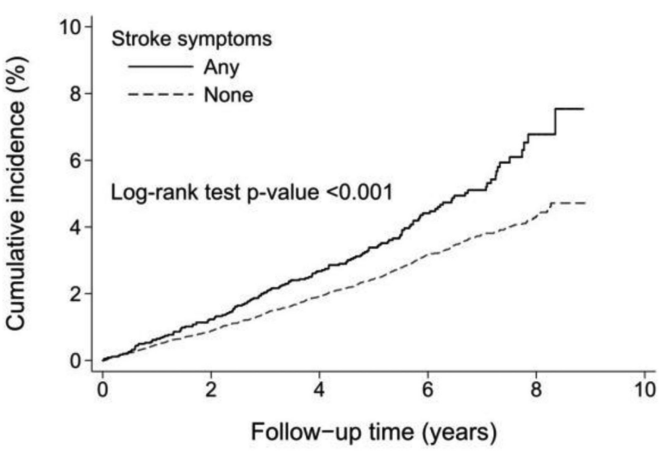

Incident CHD
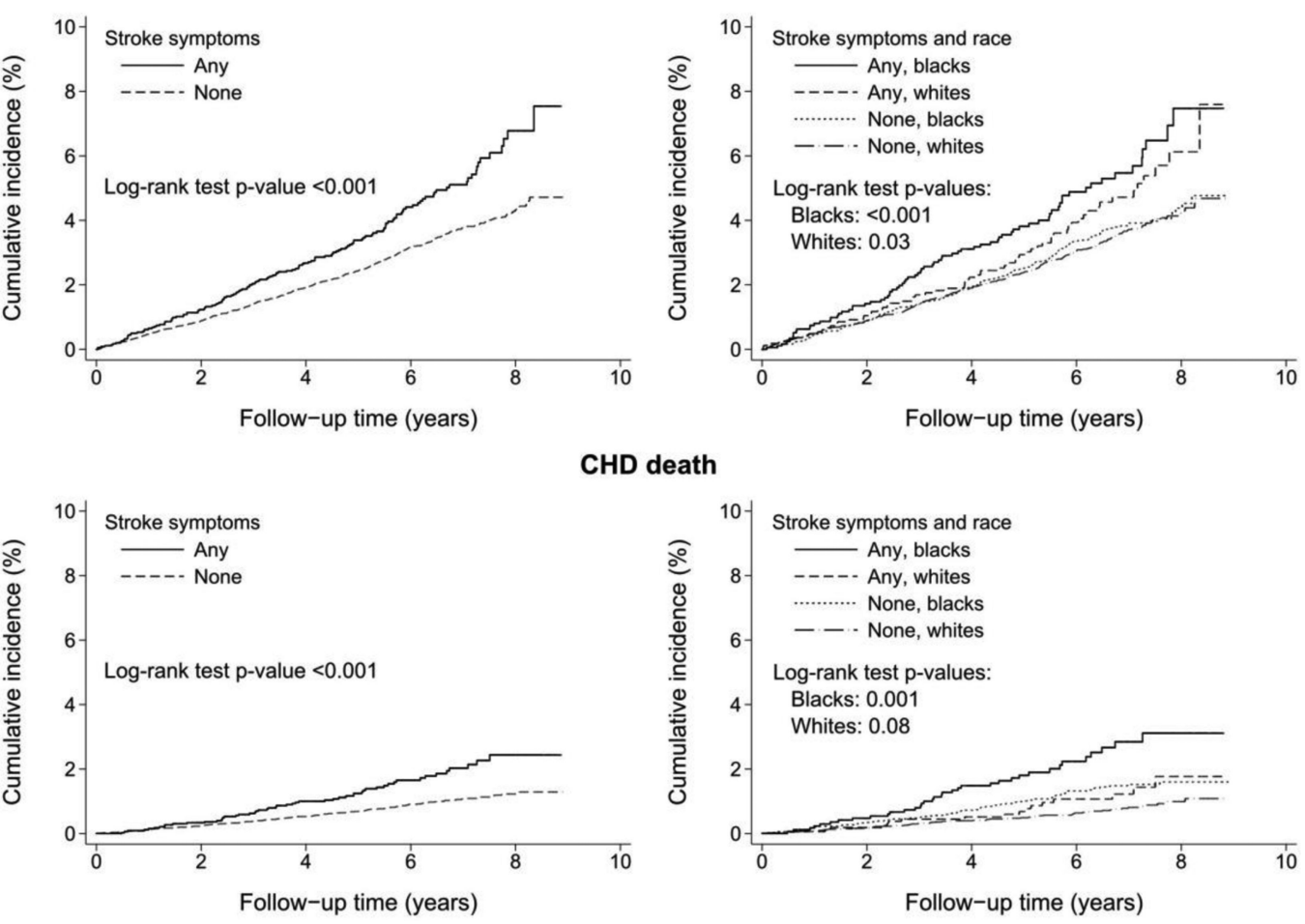

CHD death

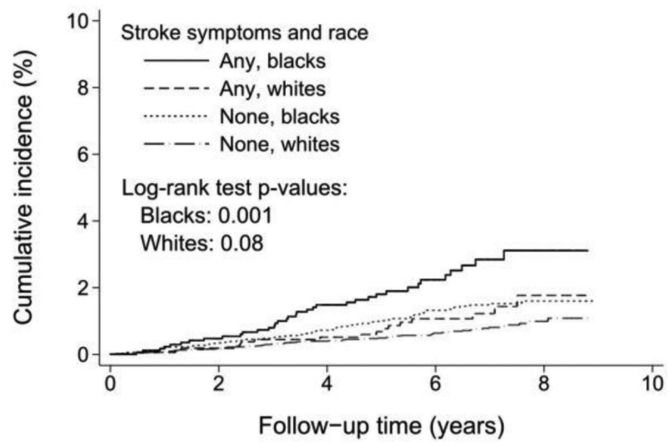

Figure 1.

Cumulative incidence of CHD (top panels) and CHD death (bottom panels) among participants with and without a history of stroke symptoms, overall (left panels) and by race (right panels). CHD: coronary heart disease. 

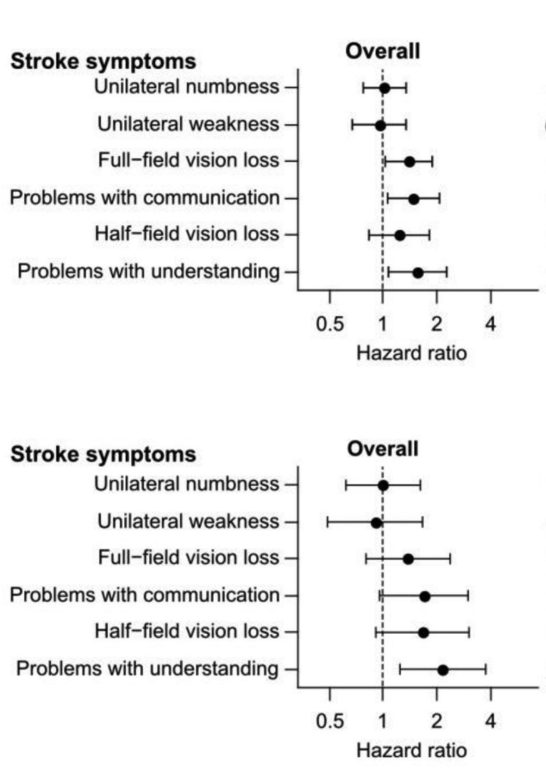

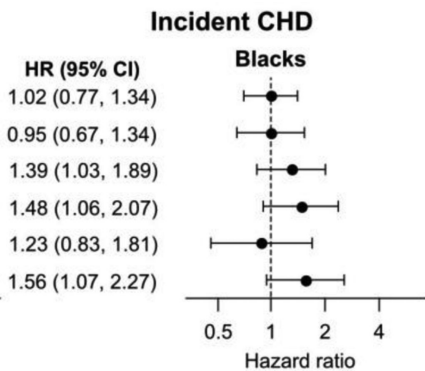

HR $(95 \% \mathrm{Cl})$
$0.99(0.70,1.40)$
$0.99(0.64,1.53)$
$1.29(0.83,2.01)$
$1.46(0.90,2.37)$
$0.88(0.46,1.70)$
$1.55(0.94,2.56)$

CHD death
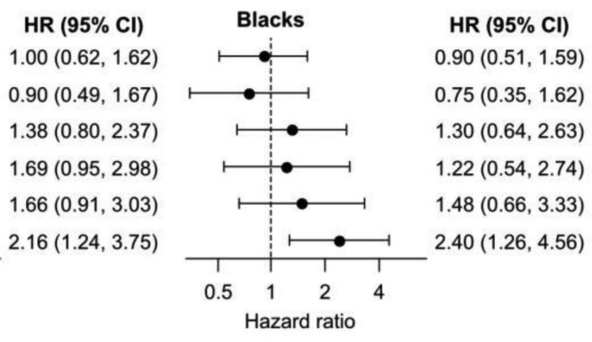

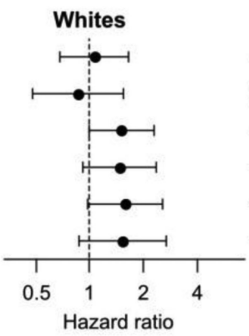

HR ( $95 \% \mathrm{CI})$ $1.06(0.68,1.65)$

$0.86(0.48,1.55)$

$1.51(0.99,2.29)$

$1.47(0.92,2.37)$

$1.58(0.97,2.55)$

$1.53(0.87,2.68)$

Figure 2.

Hazard ratios and 95\% confidence intervals for incident CHD (top panels) and CHD death (bottom panels) associated with each of the 6 stroke symptoms, overall and by race. ACR: albumin-to-creatinine ratio; CHD: coronary heart disease; $\mathrm{CI}$ : confidence interval; eGFR: estimated glomerular filtration rate; HDL: high-density lipoprotein; HR: hazard ratio; hsCRP: high-sensitivity C-reactive protein. All regression models include adjustment for age, gender, race, region of residence (i.e., stroke buckle, stroke belt and non-belt/nonbuckle), income, education, cigarette smoking, systolic blood pressure, diabetes, total cholesterol, HDL cholesterol, antihypertensive medication use, statin use, physical activity, waist circumference, ACR, hsCRP and eGFR. 


\section{Table 1}

Percentage of REGARDS study participants reporting a history of stroke symptoms, overall and by race.

\begin{tabular}{lrrr}
\hline & Overall n = 21,498 & Blacks n = 8,999 & Whites n = 12,499 \\
\hline Any stroke symptom, n (\%) & $3,432(16.0)$ & $1,771(19.7)$ & $1,661(13.3)$ \\
Stroke symptoms, n (\%) & & & \\
$\quad$ Unilateral numbness & $1,679(7.8)$ & $992(11.1)$ & $687(5.5)$ \\
Unilateral weakness & $1,088(5.1)$ & $650(7.5)$ & $438(3.5)$ \\
Full-field vision loss & $883(4.1)$ & $397(4.4)$ & $486(3.9)$ \\
Problems with communication & $707(3.3)$ & $341(3.8)$ & $366(2.9)$ \\
Half-field vision loss & $576(2.7)$ & $257(2.9)$ & $319(2.6)$ \\
Problems with understanding & $492(2.3)$ & $279(3.1)$ & $213(1.7)$ \\
\hline
\end{tabular}

REGARDS: REasons for Geographic And Racial Differences in Stroke. 


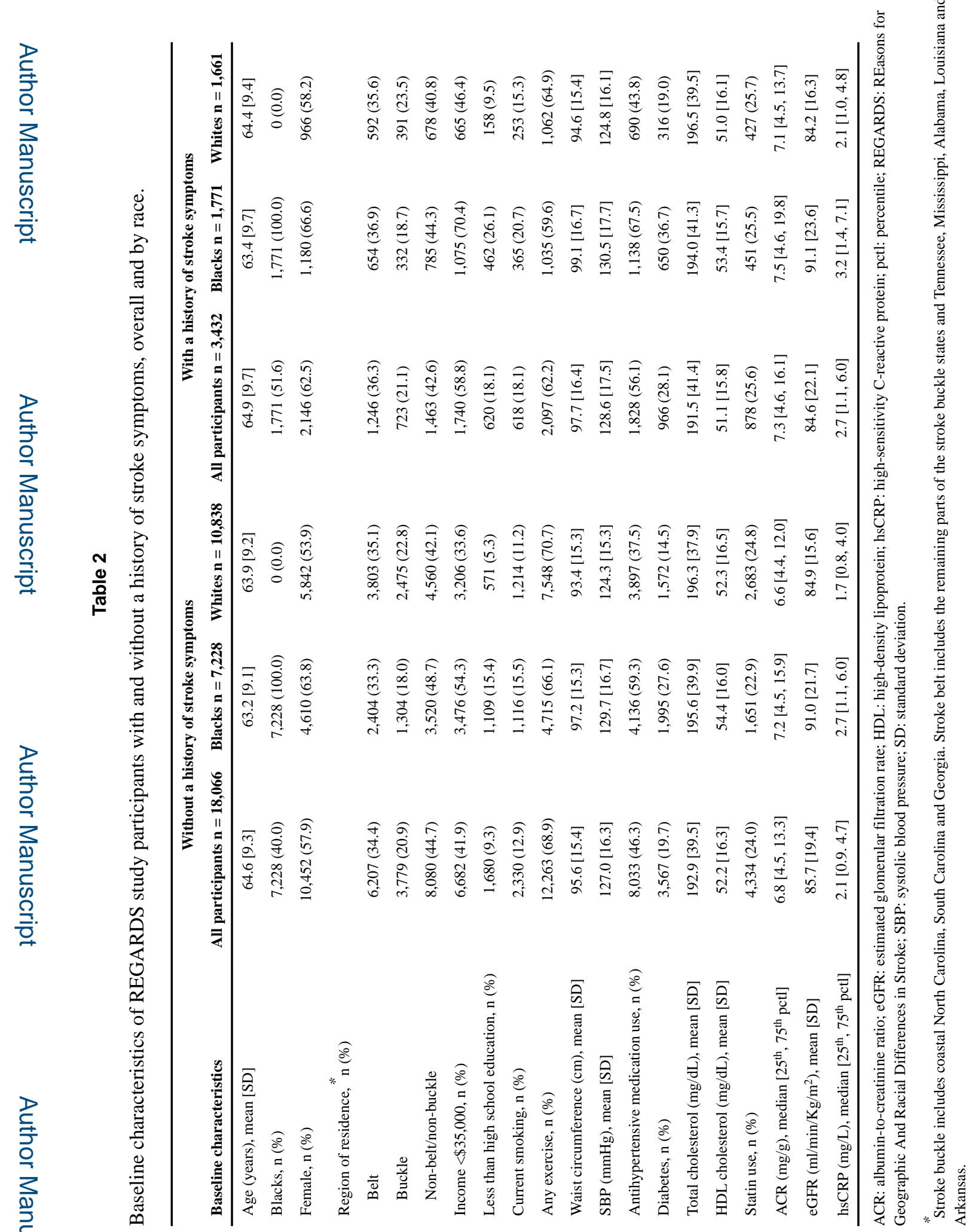

Int J Cardiol. Author manuscript; available in PMC 2017 October 01. 
Table 3

Incidence rates and hazard ratios for incident CHD and CHD death comparing REGARDS study participants with and without a history of stroke symptoms in the overall population.

\begin{tabular}{|c|c|c|}
\hline & Without a history of stroke symptoms $n=18,066$ & With a history of stroke symptoms $n=3,432$ \\
\hline \multicolumn{3}{|l|}{ Incident CHD } \\
\hline Total events, $\mathrm{n}$ & 556 & 145 \\
\hline Follow-up, person-years & 104,822 & 18,969 \\
\hline Incidence rate $(95 \% \mathrm{CI})^{*}$ & $5.3(4.9,5.8)$ & $7.6(6.5,9.0)$ \\
\hline \multicolumn{3}{|l|}{ Hazard ratio $(95 \% \mathrm{CI})$} \\
\hline Model 1 & 1 (Reference) & $1.45(1.21,1.74)$ \\
\hline Model 2 & 1 (Reference) & $1.34(1.12,1.62)$ \\
\hline Model 3 & 1 (Reference) & $1.27(1.06,1.53)$ \\
\hline Model 4 & 1 (Reference) & $1.26(1.04,1.51)$ \\
\hline \multicolumn{3}{|l|}{ CHD death } \\
\hline Total events, $\mathrm{n}$ & 156 & 53 \\
\hline Follow-up, person-years & 104,822 & 18,969 \\
\hline Mortality rate $(95 \% \mathrm{CI}){ }^{*}$ & $1.5(1.3,1.7)$ & $2.8(2.1,3.7)$ \\
\hline \multicolumn{3}{|l|}{ Hazard ratio $(95 \% \mathrm{CI})$} \\
\hline Model 1 & 1 (Reference) & $1.89(1.38,2.58)$ \\
\hline Model 2 & 1 (Reference) & $1.57(1.15,2.15)$ \\
\hline Model 3 & 1 (Reference) & $1.50(1.10,2.07)$ \\
\hline Model 4 & 1 (Reference) & $1.50(1.10,2.06)$ \\
\hline
\end{tabular}

ACR: albumin-to-creatinine ratio; CHD: coronary heart disease; CI: confidence interval; eGFR: estimated glomerular filtration rate; HDL: highdensity lipoprotein; hsCRP: high-sensitivity C-reactive protein; REGARDS: REasons for Geographic And Racial Differences in Stroke.

Model 1 is unadjusted.

Model 2 adjusts for age, gender, race, region of residence, income and education.

Model 3 adjusts for Model 2 covariates plus cigarette smoking, systolic blood pressure, diabetes, total cholesterol, HDL cholesterol, antihypertensive medication use and statin use.

Model 4 adjusts for Model 3 covariates plus physical activity, waist circumference, ACR, hsCRP and eGFR.

* Per 1,000 person-years. 


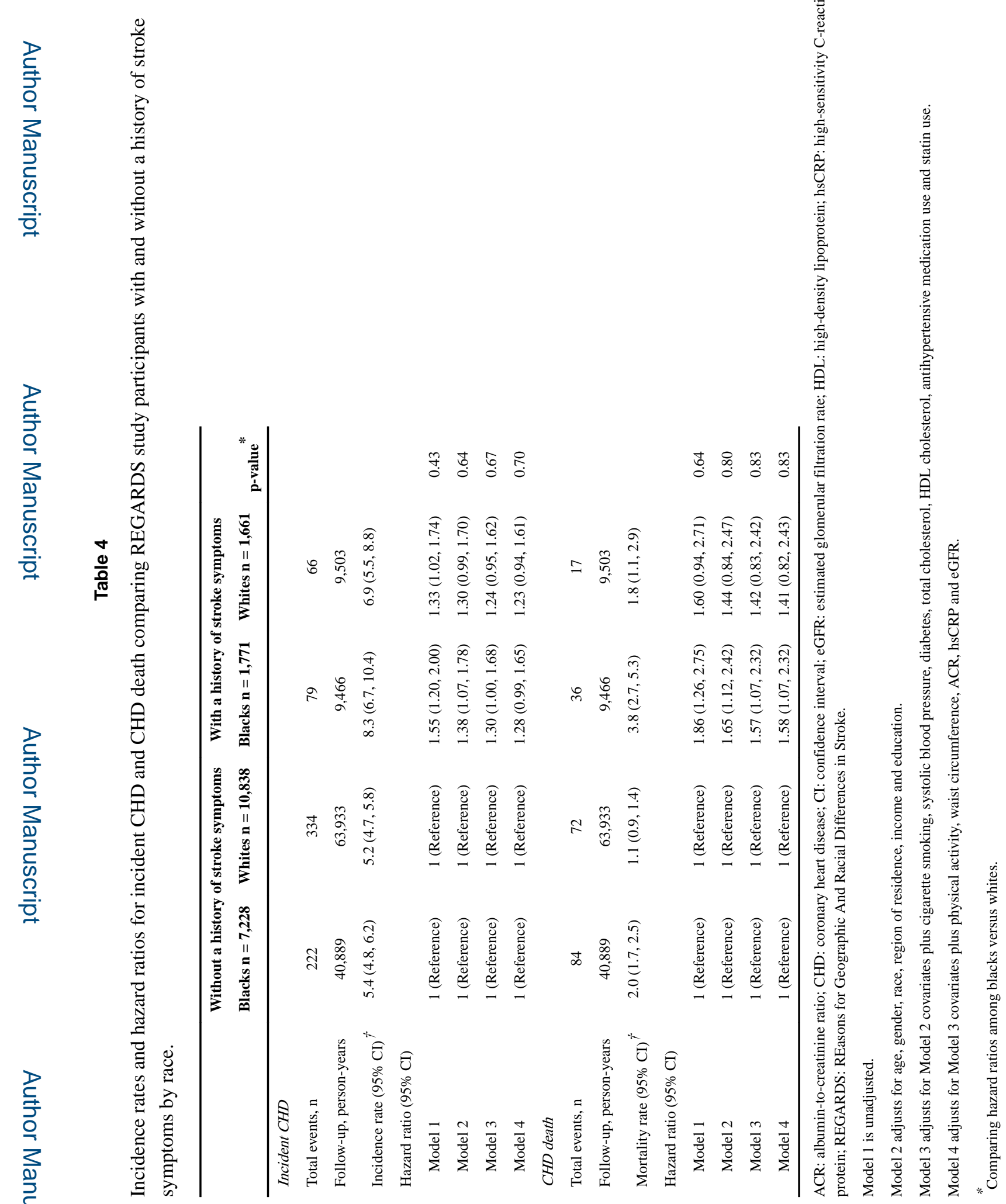

Int J Cardiol. Author manuscript; available in PMC 2017 October 01. 
